\title{
El miedo a los rumores y \\ los bandidos en Sinaloa \\ durante la Revolución \\ Mexicana de 1910-1911
}

Reymundo Darío

Velarde Camacho ${ }^{1}$

raymundo_24@hotmail.es

The fear of rumors and bandits in

Sinaloa during the Mexican Revolution

ORCID: https://orcid.org/0000-0002-2040-4585

of 1910-1911

\section{Resumen}

En el contexto de la Revolución Mexicana,

su lucha contra el gobierno porfirista. la sociedad sinaloense experimentó todo Este artículo se concentra en presentar tipo de miedos. Durante este conflicto, los rumores que se manifestaron duransurgieron algunos rumores que desataron te la revuelta maderista de 1910-1911 verdaderos pánicos. Estos rumores se y analizar las repercusiones, actitudes, propagaban para infundir temor hacia los revolucionarios, quienes arremetían con creencias y comportamientos que tuvo la población sinaloense ante los rumores, violencia contra las poblaciones para tomarlas, en su búsqueda de recursos para el padecimiento del caos y la violencia revolucionaria.

Palabras claves: miedo, rumor, violencia, revolución, bandidos.

\section{Abstract}

In the context of the Mexican Revolution, the sinaloense society experienced all kinds of fears. During this conflict, some rumors unleashed true panics. These rumors spread to instill fear of the revolutionaries, who attacked with violence, against the Porfirista government. This article focuses on presenting the rumors that emerged during the Madero revolution of 1910-1911 and analyze the repercussions, attitudes, beliefs and behaviors of the Sinaloa population, in the face of against the populations to take them in rumors and the suffering of chaos and their search of resources for their fight revolutionary violence.

Keywords: fear, rumor, violence, revolution, bandits. Universidad Autónoma de Sinaloa, México.

Av. Josefa Ortiz de Domínguez s/n. Ciudad Universitaria, C.P. 80013, Culiacán, Sinaloa, México. 


\section{Introducción}

Tras los acontecimientos que se desarrollaban en el norte de México con motivo de la revolución, en el pueblo del Quelite [Mazatlán, Sinaloa], no se oía ningún ruido por las noches, sin que causara un pánico alarmante entre sus vecinos. Ya fuera por sus habitantes que apenas podían pegar el ojo, o por el simple borrego, de que ya los tenían cerca o el más mínimo ruido del sonar de las espuelas, despertaba el miedo y el sentimiento de inseguridad entre sus habitantes. ${ }^{2}$

Durante la Revolución, en Sinaloa, la ficción, las alarmas o los rumores obtenían crédito con mucha facilidad donde el grueso de la sociedad los esparcía. Con la intención de generar temor y pánico en los pueblos de la zona serrana de Sinaloa, durante el levantamiento maderista se propagaron rumores, generalmente llamados "borregos" por la prensa local, que alarmaron a la gente sobre la aproximación de grupos revolucionarios en la Sierra Madre Occidental, a los límites con el estado de Durango, (Ojeda, 2011, pp. 156-160).

Esta clase de rumores se manifestó mediante pánico que se apoderó de una población. No obstante, este fenómeno difiere del gran pánico acontecido en la Revolución francesa, donde las alarmas se asociaron a la supuesta aproximación de bandidos y vagabundos, así como la creencia en un complot aristocrático que eliminaría al tercer estado (Lefebvre, 1986, pp. 80-103).

Abordar a la Revolución mexicana desde una narrativa del miedo, permite observar otra faceta poco conocida de este conflicto. A través de lo mental, las sensibilidades, comportamientos y mecanismos colectivos de la sociedad sinaloense de la época, también se puede acceder al fenómeno revolucionario al describir y analizar cómo el miedo a los rumores afectó la vida de esta población. Esto se hará a través de una recopilación de notas periodísticas en las que aparecen alarmas emitidas en su mayoría publicadas en El Correo de la Tarde de Mazatlán, Sinaloa, con las cuales se elaboraron cuadros y mapas donde puede visualizarse cómo se divulgaban, sobre qué hablaban, dónde y cuándo aparecían, y qué repercusiones tuvieron en las distintas poblaciones.

Para combatir al gobierno porfirista en Sinaloa, los maderistas iniciaron la lucha armada adentrándose por zonas específicas de la geografía regional. Ello dio como resultado el aumento de sensibilidad por parte de la población que resintió la violencia de los rebeldes, ya que los primeros

2 El Corresponsal. (18/02/1911). Del Quelite, El Correo de la Tarde, Mazatlán, p. 3. 
rumores aparecieron en la región de la Sierra Madre Occidental del territorio sinaloense, donde se obtuvieron los medios infalibles para difundirlos, lo que permitió extender y elevar el sentimiento de inseguridad en el estado.

\section{Imagen 1}

Federales fusilados en Mazatlán 1911

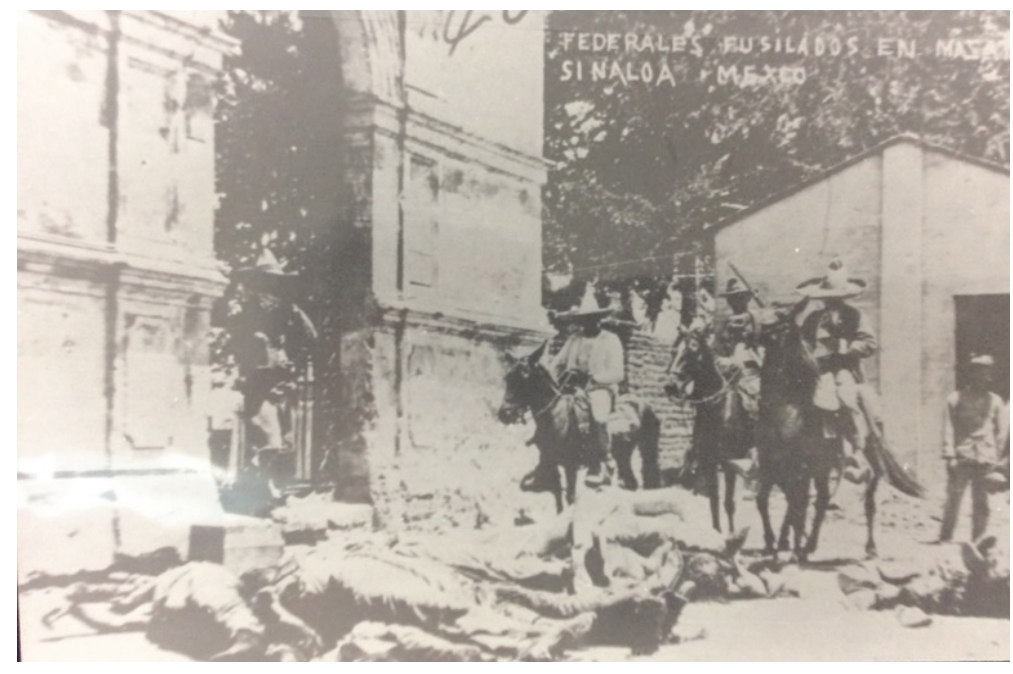

Fuente: AGN, Fondo INEHRM Fotos, Caja 8.6, Exp. 382, Foto 1/1.

Las falsas alarmas, de acuerdo con Georges Lefebvre (1986), son una red de información que se entrelaza de persona a persona, de granja en granja, del pueblo a las ciudades y que, con rapidez impresionante, logran desestabilizar toda una región, alterando el orden y poniendo en gran estado de sensibilidad a su población. Esto provoca que el miedo se torne en pánico y desate conductas referentes a la seguridad (pp. 91110). Por ejemplo, durante la Revolución francesa de 1789, cuando una población esperaba la llegada de un enemigo las personas sospechaban de todo: un individuo, una nube de polvo, un ruido, una sombra, etcétera; más si dichas personas eran centinelas, estaban cansadas o tenían muchas responsabilidades. (Lefebvre, 1986, p. 70).

De acuerdo con Jean Delumeau (2013), el rumor aparece como la confección y la explicación de una angustia generalizada y, al mismo tiempo, como el primer estadio del proceso de liberación que provisionalmente va a librar a la multitud de su miedo. Es identificación de una amenaza 
y clarificación de una situación que se ha vuelto insoportable. El rumor puede adoptar el aspecto de una alegría irracional y de una esperanza loca, pero la mayoría de las veces se convierte en espera de una desgracia (pp. 360-364).

\section{La ciudad sitiada y la exaltación}

\section{de los temores en la toma de Culiacán}

El gran miedo vivido durante la Revolución mexicana se manifestó, principalmente, por una escalada y temida violencia, pues predominaba en las zonas rurales cercanas a las inmediaciones de la ciudad, y es así como se propagó de los espacios rurales hasta la zona urbana, donde el miedo se tornó más caótico.

En el imaginario social, una idea que alimenta a las élites era la concepción de un terror que ve en los pobres una confidencialidad con los bandidos y revolucionarios, una desconfianza total cuya expresión se ve alentada en las calles, a una plebe deseosa de ver caer a los culpables de años de humillaciones, resentimiento y odio. "Es por ello que el imaginario que se crea alrededor del pueblo se vincula a la inversión del orden social establecido que se había presentado en Francia con la revolución" (Rosas, 2006, p. 154). Sin embargo, la propagación de los miedos se difunde a otros polos de la sociedad. Michel Vovelle (1989) aborda los miedos urbanos en el tiempo corto y cambiante, y señala que la violencia revolucionaria forma parte del proceso de mutación, sobre todo en las formas institucionalizadas como el terror y los tribunales revolucionarios (p. 117). Es decir, el miedo en su forma urbana se extiende a otros actores, no sólo a las clases oligárquicas y privilegiadas, sino al resto de la sociedad.

Lefebvre explica que, ante este tipo de situaciones, la inseguridad es la causa del pánico, incluso aunque se compruebe que los bandidos no llegarán; los periodos de crisis vuelven creíble su aparición (1982, p. 276). De la misma forma, en la Revolución mexicana los rumores sobre bandidos aumentaron el miedo de los pueblos serranos, incluso si éstos no aparecían. Por lo tanto, las alarmas no podían motivar otra cosa que el terror donde la tranquilidad y la vida cotidiana se interrumpía en los asentamientos; de cierta forma, debido a la violencia de los bandidos que se relacionaba a la pérdida de los bienes y al arremetimiento contra la población (Delumeau, 2013, p. 52).

Así, la principal preocupación de la capital del estado, punto más cercano a la rebelión en la sierra, era contar con la suficiente fuerza para cualquier eventualidad. Además, en poblaciones cercanas como Quila, Cosalá, Pericos y Navolato, los bandidos se internaron cada vez más al 
distrito; por ello, los rumores y la tergiversación de la realidad, publicados en su mayoría por diarios locales -como El Correo de la Tarde, para Mazatlán, y El Monitor Sinaloense, en Culiacán-, confundían a los citadinos. Algunas veces se atendía este problema mediante alguna protesta de la opinión pública, pero en general estos rumores apenas si se podían controlar, pues, como explica Claudia Rosas (2006):

en los espacios de sociabilidad se generan diversos tipos de comentarios, por un lado, encontramos incredulidad frente a las noticias que difunde la prensa oficial y, por otra parte, diversas interpretaciones de los hechos que incluyen posiciones favorables a la revolución. En las conversaciones en las calles, entre bandos y pregoneros, pasquines y periódicos, surgen los rumores y la falsa noticia (pp. 165-166).

Bajo estas condiciones de temor que invadían los centros urbanos, la población que temía padecer la violencia y tribunales revolucionarios, se desplazó a zonas consideradas más seguras. La huida y búsqueda de tranquilidad fueron actitudes que los sinaloenses tomaron para evadir los peligros de la Revolución, pues en concordancia con Jean Delumeau (2013), la seguridad se define como símbolo de vida, mientras la inseguridad como símbolo de muerte, donde el miedo es una muralla esencial contra los peligros y la muerte. (pp. 22-23). Alcanzar el mar fue lo predominante para las familias de clase oligárquica que escapaban de las ciudades, siendo los puertos de Altata y Mazatlán los más socorridos para refugios y vías de escape hacia el exterior, como Estados Unidos.

Este tipo de situaciones no eran propias de la Revolución mexicana, y se vieron con mayor frecuencia a lo largo del siglo xx, donde la población, temerosa de la guerra, se desplazó a lugares más seguros. Por ejemplo, durante la Segunda Guerra Mundial, con la inminente derrota francesa, "existió una fiebre por la evasión, situación que surgía por una preocupación de la población francesa para huir del cautiverio de los alemanes, hacia el único camino que seguía expedito, el del mar" (Bloch, 2003, p. 70).

En mayo de 1911, un contingente de más de mil hombres liderado por Ramón F. Iturbe, descendió de la sierra para liquidar al antiguo régimen; casi al mismo tiempo otros grupos revolucionarios hicieron lo mismo en el puerto de Mazatlán (Olea, 2010, pp. 62-64). En ambos casos, la sociedad sinaloense padeció crudas expresiones de angustia e incertidumbre de la violencia maderista. Es precisamente en el interior de las ciudades que los habitantes experimentaron un sobrecogimiento ante la situación.

El miedo permeó lo suficiente como para aislar a la población del exterior y del acceso a la información. A mediados de abril, el correo y los 
periódicos dejaron de circular en la capital del estado. Las autoridades funcionaban a medias y los militares sólo se ocupaban de la revuelta. Varios funcionarios del gobierno y numerosas familias de la élite huyeron temerosas de sus vidas hacia el extranjero. Las calles de la ciudad lucieron semi vacías, y los comercios cerraban por la inseguridad. Así, la casa particular fue el lugar más seguro (Molina, 2003, p. 107). En este sentido, la revolución representa un corte profundo en la existencia, una ilustración social del "sálvese quien pueda" (Vovelle, 1989, p. 210).

Ante esta situación se presentó el tratado de paz a los defensores, pero temiendo un ardid de los revolucionarios, los porfiristas no aceptaron, por lo que los rebeldes retomaron las hostilidades el 23 de mayo de 1911. Tras días de combates, el gobernador Diego Redo entregó la capitulación el 31 de mayo a las 10 de la noche. Como si esa fuera la señal, los maderistas junto a una muchedumbre descontrolada, saquearon las casas comerciales y particulares, por lo que se vivió un periodo de anarquía mientras se fusilaba a los soldados federales. ${ }^{3}$

\section{Los rumores, la revolución y el gran miedo}

Para Gordon Allport y Leo Postman (1988) el rumor es un problema social que afecta principalmente en momentos difíciles, cuando existe una avidez de noticias que estimula la imaginación y afecta la moral de la gente, creando alarmas o vagas esperanzas. Para ellos el rumor conducía al error, pues se alejaba de la verdad y distorsionaba sucesivas interpretaciones subjetivas; llega como noticia con la intención de despejar la incertidumbre y calmar la ansiedad que provoca miedo.

Por otra parte, Javier Contreras (2001) señala que definir un rumor no es fácil, pues llega a ser reconocible cuando lo encontramos y, por lo general, no hay algún consenso de cómo delimitarlo con precisión, dónde comienza y dónde acaba el fenómeno. Analiza cómo los rumores se expanden y desarrollan en los tiempos modernos, enumerando diversas utilidades desde diferentes ámbitos, como la guerra, la propaganda, la mercadología; pero es desde la política donde define al rumor como un fenómeno que crea disturbios y se le identifica como una comunicación que serpentea diferentes formas, que penetra y crea dudas a medida que se regenera con nuevos datos (pp. 3-6).

En contraste, Margarita Zires (1995) aborda el rumor desde la cultura y, al igual que Contreras, sigue los preceptos que dejaron Allport y G. Chequellin. (14/06/1911). Culiacan Looted. Spokane Daily Chronicle, Spokane Fall, Oregon, p. 19. 
Postman, quienes estudiaron los rumores en la Segunda Guerra Mundial. Zires se centra en los elementos culturales de los estadunidenses como factor integral para el surgimiento de ciertos rumores. Se menciona el ejemplo del profesor chino que es confundido con un espía japonés; Zires afirma que dentro de una sociedad hay componentes culturales que trabajan dentro del inconsciente colectivo que ayudan a moldear ideas, las cuales se ven influenciadas o potenciadas por medios como el cine, la prensa, la propaganda, la radio, etc., y de esta forma transmiten ciertos elementos que bajo una situación de guerra configuran los rumores.

Concretamente en Sinaloa, las alarmas se asociaron con la aparición de rebeldes cuyos ataques consistieron en la toma de pueblos, búsqueda de armas o provisiones; los cuales en su práctica se asemejaban a los bandidos del siglo XIX, donde el recuerdo de este temor volvía para apoderarse de la población (funcionarios públicos, terratenientes, extranjeros, comerciantes y pobladores), sumándose la idea de una venganza popular y tribunal revolucionario que consistía en el resentimiento de las clases populares, cuyo fin tendía a resolver agravios entre los campesinos enfurecidos y las clases oligárquicas (Knight, 2010, p. 302).

Los miedos de la sociedad sinaloense durante la Revolución llegaban, primero, a través de los sentidos por medio de los rumores, la ficción, las alarmas o borregos, los cuales preceden a los hechos de armas en el estado. Los corresponsales de la prensa trasmitieron la verdad de lo que estaba pasando en la Sierra Madre creando miedo, y elevaban la sensación de inseguridad mediante su difusión.

En cuanto a la producción de la noticia, Teun Van Dijk (1990) explica que tiene mucho que ver cómo se dicen las cosas, desde la elección de un estilo hasta el contexto de una situación particular, la cual se utiliza para mandar un mensaje efectivo a nivel cognitivo que sirve para que el lector construya una representación textual bajo la intención del escritor, siendo copartícipe y comprenda que lo que él dice tiene la intención de ser una afirmación o una amenaza (p. 123), por ello,

En el campo de la producción de la noticia los periodistas y lectores a través de las cogniciones sociales participan en el discurso. Dentro de la estructura de la noticia se relacionan las prácticas sociales y la ideología de la producción de noticias con el contexto institucional y los medios periodísticos. En este sentido la noticia o discurso periodístico se diferencia de otros relatos, puesto que es una clase específica de discurso de los medios de comunicación de las masas para causar un impacto (Van Dijk, 1990, pp. 9-11). 
Concretamente El Correo de la Tarde era uno de los principales diarios del puerto que difundía rumores recopilados por los corresponsales acerca de la actividad de los revolucionarios maderistas en la Sierra Madre. Es posible que este diario dirigido por el periodista Heriberto Frías, conocido Ultra-Ferrelista que abrazó la causa maderista y lanzó duras críticas al régimen porfirista y al gobernador de Sinaloa Diego Redo, publicara estas noticias no sólo para informar de la guerra, sino para inculcar el miedo en las élites dirigentes (Quintero, 2007, pp. 355-356).

Por lo tanto, es necesario responder la siguiente pregunta: ¿Qué rol cumplía la difusión de los rumores en las noticias periodísticas? De acuerdo con Van Dijk (1990), las noticias construyen parte de un marco del mundo social, donde la prensa puede manipular información, la forma física de los objetos y la selección de los temas para poder enviar un mensaje que el lector recibirá y representará con base en esos elementos (pp. 10-20). Desde la producción de la noticia, la prensa del puerto transmitía y recogía estos rumores para despertar inseguridad, sobre todo en el lugar urbano, ya fuera Culiacán o Mazatlán. El miedo era dirigido hacia los lectores urbanos, a donde se expandía al resto de la población, pues de esa manera asimilaban una idea real, que transformaba la estructura social y producía alteraciones en la conducta y el imaginario colectivo.

La prensa local relacionaba a los animales con el estado emocional de un pueblo o de las personas; por ejemplo, a los "borregos lanudos" se les describía para resaltar sensaciones como miedo, desasosiego, malestar e inseguridad, ${ }^{4}$ por lo que el borrego representaba la docilidad, mansedumbre, habitualidad para ser sometidos y guiados por el miedo a comportamientos de rebaño.

El miedo a la propagación de rumores o alarmas durante la revolución maderista no era privativo de Sinaloa, pues también ocurría en otras regiones, como Jalisco, caso estudiado por Vargas (2012). Según él, este temor en Jalisco nacía de un momento que amenazaba el estado de conservación de una sociedad; es decir, que las acciones realizadas por los revolucionarios llevaban al reino de las conjeturas, rayando el plano de la fantasía y la ficción, o al menos, eso hacía suponer la prensa de la época con tintes de humor y de temor (p. 66).

Por ejemplo, Vargas (2012) menciona que a principios de diciembre de 1910, una amenaza cobró intensidad en la ciudad de Guadalajara debido a una nota periodística que decía que "los maderistas tenían una máquiCaso contrario, el gallo se refería a la fiesta, a la alegría, a la certidumbre de los ranchos y pueblos, por lo que representa el buen humor, el canto, las festividades, entre otros elementos que juegan con este simbolismo. 
na infernal, con la que destruirán el gobierno de Díaz". El autor explica que los periódicos publicados en Guadalajara, aparte de informar, se encargaban de distribuir conjeturas y medidas tomadas por los habitantes de la ciudad, que, si bien daban cuenta de que las autoridades hacían lo posible por encontrar y atrapar a los conspiradores, sólo lograron acrecentar la incertidumbre, debido a que la policía buscaba sospechosos. Esta situación contribuyó a la generación de noticias sobre un levantamiento armado (p. 62).

Tomando como referencia el caso de Jalisco, en Sinaloa, conforme la rebelión se fue extendiendo, comenzaron a aparecer y circular en los pueblos, ranchos y aldeas, rumores sobre el movimiento de revolucionarios y sus actividades. A partir de los primeros asaltos a los poblados de la sierra, surgieron las primeras noticias alarmantes sobre la actividad de los rebeldes, que conforme aumentaba, se extendió en la mentalidad de los sinaloenses y a elevar el sentimiento de inseguridad en la región.

Estos rumores empezaron a proliferar en Sinaloa desde los últimos días de 1910. En el mineral de Pánuco (Concordia, Sinaloa), los pobladores disfrutaban de las funciones del circo Victoria el 30 de diciembre de 1910, cuando circuló por las calles del pueblo una alarma sobre unos bandidos que se encontraban en el rancho Los Naranjos, punto más allá de Cópala (Concordia), de donde se sospechaba eran los responsables por el robo de ganado, mulas y caballada de aquel lugar. El director político y algunos auxiliares junto a la autoridad de Cópala emprendieron su búsqueda para su aprehensión.

Los habitantes de Pánuco asociaron a los bandidos con los rebeldes de Chihuahua; cuando el movimiento maderista estaba en pleno auge en el norte de México, en Sinaloa los levantamientos armados estallaron hasta el mes de enero de 1911. La sociedad sinaloense padeció el miedo a la revolución a través de los sentidos y la proliferación de los rumores antes de que ocurrieran los hechos armados. Mediante las noticias que llegaban del otro lado de la de la sierra, más allá de la frontera política y geográfica de Sinaloa, los serranos asociaron la presencia de bandidos y extraños con los revolucionarios. El rumor despertaba incertidumbre entre los habitantes por su difusión, y se hacía creíble debido a la certeza de que los bandidos merodeaban la zona serrana, donde el miedo se acrecentaba, incluso sin que existieran hechos violentos.

En Pánuco este rumor causó gran temor entre el comercio del pueblo, y se relacionó con los rebeldes de Durango y Chihuahua, lo que produjo angustia cuando se organizó un grupo de búsqueda. Al final el director político y los voluntarios volvieron sin ninguna novedad. Después de revisar aquellos contornos, quebradas y vericuetos donde no se supo nada de 
aquellos bandidos; pareciera que habían desaparecido o se los hubiera tragado la tierra. ${ }^{5}$ En ese sentido,

En el rumor hay muchos fragmentos de verdad, que requieren, una dosis de verdad como "pie de cría" o semilla, aunque lo que siga posteriormente se vaya alimentando de fantasías. La misma preocupación que despierta la circulación de un rumor fortalece la posibilidad de que contenga algo de verdad o simples mentiras. El problema del rumor es que se vuelve molesto porque su mensaje puede tener fundamentos y también molestan porque se trata de una información que está fuera del control del poder (Contreras, 2001, p. 12).

A mediados de enero de 1911, en Cosalá se recibieron algunos telegramas donde se informaba que rumbo a Tamazula, Durango, donde los habitantes no pondrían resistencia debido a la falta de armamento, se dirigieron quince hombres armados que se presumía eran gente de Juan Banderas. También se sabía que cerca de Guadalupe los Reyes (Cosalá) merodeaban otros rebeldes con intenciones de tomar el lugar que carecía de elementos de defensa y se deducía que el número de rebeldes era de sesenta. ${ }^{6}$

Al igual que en el caso de Pánuco, el prefecto de Cosalá examinó el área. Por aquellos meses, la población de la sierra del lado de Sinaloa se encontraba en constannte alarma, ya que los primeros movimientos revolucionarios ocurrían en lugares donde no había fuerza que opusiera resistencia por falta de armas y elementos de seguridad. La lejanía y lo remoto de estos lugares constituyeronfactores importantes para que estas bandas proliferaran sin obstáculo alguno, donde las fuerzas federales en el estado tardaban en responder al llamado de auxilio de los pueblos en la sierra.. P Por ejemplo,, Tamazula resistió varios ataques del rebelde sinaloense Ramón F. Iturbe, hasta que fue ocupada en marzo de 1911.

En otro escenario, lejos del ámbito serrano y rural, las ciudades también se vieron afectadas por estos rumores; por ejemplo, una alarma que circuló en Mazatlán el 7 de enero de 1911 atemorizó al vecindario de la siguiente manera:

Algunas gentes y hasta varios gendarmes, según nos dicen, se alarmaron la otra noche en que se efectuaba la representación en el Tívoli Mazatleco del drama El sueño de Iturbide; pues cuando oyeron Editorial. (3 de enero de 1911). De Pánuco. El Correo de la Tarde, Mazatlán, p. 3. (23 de enero de 1911). El Correo de la Tarde, p. 4. 
los toques de tambores y cornetas y la descarga que siguió después, creyendo que los revoltosos habían penetrado a la ciudad y puerto de Mazatlán los honrados vecinos que a esa hora ya se encontraban acostados, pero con el ojo abierto, escondieron la cabeza entre las sabanas y se hicieron ovillo, y algunas cotorronas que ya se mueren de ganas porque se las lleve el diablo, saltaban ligeramente de sus lechos creyendo que había llegado ya el momento de que se las llevara a la grupa de un chato revoltoso. De los gendarmes nos dicen que hubo quienes se aprestaron para hacer frente al enemigo, pero otros no hallaban por dónde escapar, dizque para que no les quitaran las armas. ${ }^{7}$

A finales de enero de 1911, en Culiacán, los altos círculos sociales creían el rumor de que los rebeldes, después de estar en Tamazula, proseguirían su marcha hacia la capital sinaloense. Este temor se nutría debido a una nota que informaba que los revolucionarios se encontraban de camino a Guayabastita (Durango), a ocho horas de la capital sinaloense. ${ }^{8}$ El periódico también reportó la constante actividad de Juan Banderas y los suyos, que merodeaban por la frontera de Durango, bola que sumaba 300 hombres y contaba con mulas cargadas de carabinas para armar a sus adeptos. ${ }^{9}$

Las falsas noticias alarmaban a los habitantes de Culiacán y Mazatlán, debido a que los rumores se difundían más en la ciudad que en las zonas rurales, porque los periódicos estaban dirigidos al público lector de las urbes. Además, traspasaban los diferentes estratos sociales al propagarse a toda la población por medio de los comentarios, charlas o pláticas en los mercados, cantinas, iglesias, plazas o calles, donde los borregos solían transmitirse y llegar a más personas. El miedo se arraigó con fuerza entre la población urbana debido a la idea de que el orden porfiriano había traído la paz, seguridad y tranquilidad social, y que ante la llegada del caos revolucionario, fuera a romperse, permeando en el inconsciente de la sociedad la espera de un porvenir angustioso. Por ejemplo:

Anoche corrió por segunda vez la alarmantísima noticia de que los revoltosos habían tomado Navolato, cometiendo toda clase de atropellos. No sé cuál sería el origen de ese rumor, pues hasta las autoridades se alarmaron, porque hubo mucho movimiento de gente armada y, se

7

Editorial. (05 de febrero de 1911). Una pequeña alarma. El Correo de la Tarde, Mazatlán, p. 2.

8 El Otro. (05 de febrero de 1911). De Culiacán. El Correo de la Tarde, Mazatlán, p. 3.

$9 \quad$ El Otro. (20 de febrero de 1911). De Culiacán. El Correo de la Tarde, Mazatlán, p. 1. 
armó un convoy, que ya estaba listo para conducir cincuenta soldados del 7mo batallón; pero en esos momentos se averiguó que no era más que un enorme y bien nutrido borrego. ¡Mucho cuidado, don Tacho! ${ }^{10}$

Los rumores transgredían la cotidianidad de los sinaloenses debido a que se informaba cómo avanzaba y se acercaba cada vez más la rebelión, así como la violencia y la inseguridad que se vivía en las zonas serranas y rurales de Sinaloa, por lo que dentro de Culiacán las personas se hacían más susceptibles al miedo. Por ejemplo, El Monitor Sinaloense publicó que los borregos también era incitados por gente que quería aprovecharse de la situación para provocar temor entre la población:

No faltando quienes al saber que los revoltosos habían entrado a Topia [Durango], aseguran que la plaza de Culiacán se encuentra amenazada y que de un momento a otro vienen a hacerse dueños de la situación. Si en vez de echarse a engordar semejantes borregos, hijos del miedo, unos y de la chismografía, otros, mejor fuera que cada quien procurará ir informarse en buenas fuentes que a nadie se le niegan las noticias y dejar en paz a los revoltosos, que son más prudente de lo que se supone. ${ }^{11}$

Bajo la certeza de que los revolucionarios actuaban con mucha violencia cuando se adentraban en los pueblos, en una ocasión la población de Cosalá estaba muy alarmada por la presencia de un grupo rebelde en Chacala (Tamazula, Durango) y, temiéndose la toma de la plaza que carecía de recursos para defenderse, por la tarde se apoderó de las personas un terrible pánico originado por el aviso de un explorador que dijo haber visto una tropa armada. Ese mismo día la pequeña guarnición tomó actitudes defensivas, mientras en la calle se observaban escenas curiosas, dado que se especulaba que la tropa rebelde cargaría contra la ciudad, pero dicha tropa resultó ser una familia que venía de San José, huyendo de la bola revolucionaria. ${ }^{12}$

En este sentido, se elaboró un mapa señalando los principales lugares afectados donde se vivió el miedo por la presencia de rebeldes maderistas que se extendieron por Sinaloa. La región serrana, la zona de los valles y la costa fueron los lugares donde los rumores lograron manifestarse entre enero y mayo de 1911. En las primeras incursiones y tomas de

10

11

12

El Corresponsal. (8 de marzo de 1911). Alarma. El Correo de la Tarde, Mazatlán, p. 2.

Editorial. (16/03/1911). Siguen los borregos. El Monitor Sinaloense, Culiacán, p. 1.

El Otro. (6 de febrero de 1911). La bola. El Correo de la Tarde, Mazatlán, p. 3. 
pueblos, aparecieron con mayor frecuencia los borregos o rumores en las áreas serranas, debido a que los rebeldes y bandidos merodeaban por la topografía accidentada de la Sierra Madre Occidental en busca de armas, dinero y pertrechos de guerra.

\section{Mapa 1}

Cartografía del miedo en el levantamiento maderista

- Zona revolucionaria

de diciembre a marzo de 1911
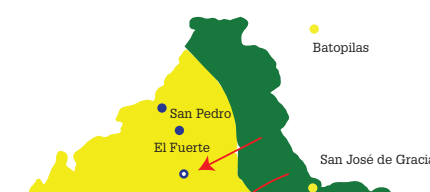

- Los Moch

San Blas

Mochis

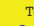

Topolobampo
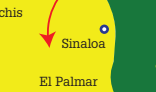

$\bullet$
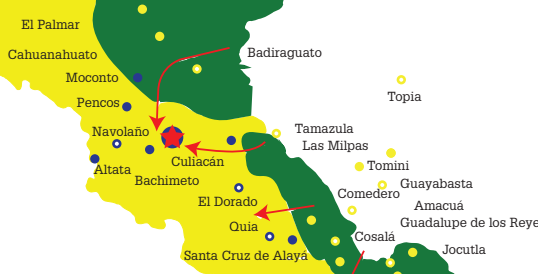

-
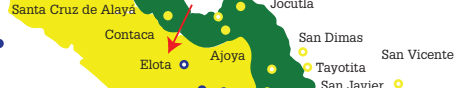

Zona revolucionaria

de abri a mayo de 1911

— Desplazamiento revolucionario

Fuente: Elaboración propia a partir de los datos encontrados en las notas del periódico El Correo de la Tarde.

En los siguientes cuadros se muestran algunos de los borregos aparecidos en El Correo de la tarde, y analizan cómo se manifestó el miedo durante la revolución maderista en Sinaloa a través de la prensa, y cuáles fueron los resultados que desempeñaron en la región. Es importante destacar que durante el alzamiento maderista de 1911, los rumores se extendieron por todo el territorio sinaloense, proliferando principalmente al inicio de la revuelta por los distritos serranos, y moviéndose entre la frontera del vecino estado de Durango para desplazarse en primavera hacia los valles y la costa. 


\section{Cuadro 1}

Los rumores en la Revolución

\begin{tabular}{|c|c|c|c|c|c|}
\hline Lugar & Fecha & Autor & $\begin{array}{l}\text { Tipología del } \\
\text { rumor }\end{array}$ & $\begin{array}{l}\text { Actitud de } \\
\text { la población }\end{array}$ & $\begin{array}{l}\text { Propaga- } \\
\text { dor }\end{array}$ \\
\hline Copala & $03 / 01 / 1911$ & bandidos & robo & $\begin{array}{l}\text { lucha y } \\
\text { alarma }\end{array}$ & prensa \\
\hline $\begin{array}{l}\text { Guadalupe } \\
\text { los Reyes }\end{array}$ & 06/01/1911 & individuos & aproximación & alarma & telégrafo \\
\hline Culiacán & $11 / 01 / 1911$ & maderistas & aprehensión & angustia & prensa \\
\hline Panuco & $31 / 01 / 1911$ & maderistas & saqueo(a) & angustia & vecinos \\
\hline Tamazula* & $01 / 02 / 1911$ & Juan Banderas & ataque (a) & angustia & telégrafo \\
\hline $\begin{array}{l}\text { Guadalupe } \\
\text { los Reyes }\end{array}$ & $01 / 02 / 1911$ & Juan Banderas & aproximación & angustia & telégrafo \\
\hline Culiacán & 05/02/1911 & revolucionarios & aproximación & alarma & vecinos \\
\hline Cosalá & 06/02/1911 & revolucionarios & ataque (a) & $\begin{array}{l}\text { alarma y } \\
\text { defensa }\end{array}$ & prensa \\
\hline Mazatlán & 07/02/1911 & revolucionarios & borregos & alarma & prensa \\
\hline Rosario & $10 / 02 / 1911$ & individuos & aproximación & angustia & vecinos \\
\hline Amaculí* & $10 / 02 / 1911$ & Juan Banderas & ataque & huida & prensa \\
\hline Cosalá & $10 / 02 / 1911$ & revolucionarios & ataque & $\begin{array}{l}\text { huida y } \\
\text { lucha }\end{array}$ & prensa \\
\hline Mazatlán & $10 / 02 / 1911$ & individuos & $\begin{array}{l}\text { asalto en } \\
\text { camino }\end{array}$ & angustia & $\begin{array}{l}\text { parte } \\
\text { oficial }\end{array}$ \\
\hline Aguaverde & $10 / 02 / 1911$ & individuos & aproximación & expectación & vecinos \\
\hline Elota & $12 / 02 / 1911$ & revuelta & borregos & angustia & prensa \\
\hline Quila & $13 / 02 / 1911$ & revolucionarios & borregos & angustia & prensa \\
\hline Conitaca & $16 / 02 / 1911$ & revolucionarios & borregos & angustia & prensa \\
\hline Concordia & $17 / 02 / 1911$ & revuelta & $\begin{array}{l}\text { servicio de } \\
\text { armas (b) }\end{array}$ & huida & telégrafo \\
\hline Quelite & $17 / 02 / 1911$ & revolucionarios & borregos & alarma & vecinos \\
\hline Rosario & $21 / 02 / 1911$ & revuelta & $\begin{array}{l}\text { servicio de } \\
\text { armas }\end{array}$ & angustia & vecinos \\
\hline Culiacán & $22 / 02 / 1911$ & revuelta & $\begin{array}{l}\text { retraso del } \\
\text { tren }\end{array}$ & alarma & prensa \\
\hline Quila & $23 / 02 / 1911$ & bandidos & robo & lucha & prensa \\
\hline $\begin{array}{l}\text { Badira- } \\
\text { guato }\end{array}$ & $28 / 02 / 1911$ & revolucionarios & ataque & $\begin{array}{l}\text { serenidad y } \\
\text { defensa }\end{array}$ & prensa \\
\hline Rosario & 01/03/1911 & maderistas & borregos & $\begin{array}{l}\text { alarma y } \\
\text { defensa }\end{array}$ & prensa \\
\hline
\end{tabular}




\begin{tabular}{|c|c|c|c|c|c|}
\hline Lugar & Fecha & Autor & $\begin{array}{c}\text { Tipología del } \\
\text { rumor }\end{array}$ & $\begin{array}{c}\text { Actitud de } \\
\text { la población }\end{array}$ & $\begin{array}{c}\text { Propaga- } \\
\text { dor }\end{array}$ \\
\hline $\begin{array}{l}\text { San José } \\
\text { de Gracia }\end{array}$ & 01/03/1911 & rebeldes & ataque & $\begin{array}{l}\text { lucha y } \\
\text { defensa }\end{array}$ & prensa \\
\hline Rosario & 04/03/1911 & gavilla & ataque & $\begin{array}{l}\text { lucha y } \\
\text { defensa }\end{array}$ & telégrafo \\
\hline Culiacán & 04/03/1911 & individuos & saqueo & alarma & prensa \\
\hline Quelite & 05/03/1911 & revoltosos & $\begin{array}{l}\text { servicio de } \\
\text { armas }\end{array}$ & lucha & $\begin{array}{l}\text { parte } \\
\text { oficial }\end{array}$ \\
\hline $\begin{array}{l}\text { Guadalupe } \\
\text { los Reyes }\end{array}$ & 05/03/1911 & revoltosos & saqueo & expectación & vecinos \\
\hline Navolato & 06/03/1911 & revoltosos & ataque & $\begin{array}{l}\text { alarma y } \\
\text { lucha }\end{array}$ & prensa \\
\hline Pánuco & 08/03/1911 & revuelta & $\begin{array}{l}\text { servicio de } \\
\text { armas }\end{array}$ & $\begin{array}{l}\text { alarma y } \\
\text { huida }\end{array}$ & Prensa \\
\hline
\end{tabular}

(*) Perteneciente a Durango, (a) aproximación, (b) borregos.

Fuente: elaboración propia a partir de datos recopilados del periódico El Correo de la Tarde de Mazatlán, Sinaloa, entre los meses de enero y mayo de 1911.

¿Qué impacto tuvieron los rumores y cómo afectaron a la población sinaloense? Éstos constituyeron uno de los temores que se presentó con más constancia, y el más asociado durante etapas tempranas en todas las revueltas armadas en el estado, de 1911 hasta 1917. Llegaron al inconsciente de la sociedad y alteraron su vida cotidianidad. El rumor y el miedo se pueden personificar como un rostro humano que los convierte en un peligro latente. Este miedo se debió quizás a un constructo del imaginario colectivo sobre lo que ellos creían eran revolucionarios, muchas veces identificados como revoltosos, rebeldes, maderistas, bandidos o, a veces, se daba un rostro humano para asociarlos, como fue el caso de Juan Banderas o Ramón F. Iturbe.

El miedo y las alarmas en Sinaloa se basaron en situaciones reales, por ejemplo, cuando un individuo en San Ignacio exclamó que: "los corresponsales de El Correo de la Tarde se inspiraban en lo verdadero y el público se encontraba ávido de sucesos rigurosamente exactos". ${ }^{13}$ Según Contreras (2001), "una de las formas más efectivas de comunicar algo es recurrir al sistema más elemental y antiguo: el de persona a persona o el de boca a boca, para conservar el estilo puro, fresco y espontáneo de la comunicación humana". Era un medio tan rudimentario y efectivo que se

13 Editorial. (30 de marzo de 1911). De San Ignacio. El Correo de la Tarde, Mazatlán, p. 2. 


\section{Cuadro 1.2}

Los rumores en la revolución parte 2

\begin{tabular}{|c|c|c|c|c|c|}
\hline Lugar & Fecha & Autor & $\begin{array}{l}\text { tipología del } \\
\text { miedo }\end{array}$ & Respuesta & Medio \\
\hline Culiacán & 09/03/1911 & revoltosos & aproximación & serenidad & prensa \\
\hline Pánuco & 09/03/1911 & individuos & borregos & $\begin{array}{l}\text { alarma y } \\
\text { lucha }\end{array}$ & prensa \\
\hline las Flechas & 10/03/1911 & maderistas & robo & expectación & prensa \\
\hline Badiraguato & 10/03/1911 & revoltosos & ataque & expectación & prensa \\
\hline Mocorito & 12/03/1911 & $\begin{array}{l}\text { revoluciona- } \\
\text { rios }\end{array}$ & borregos & $\begin{array}{l}\text { alarma y } \\
\text { defensa }\end{array}$ & prensa \\
\hline Culiacán & 13/03/1911 & revuelta & ataque & expectación & telégrafo \\
\hline Culiacán & 24/03/1911 & revoltosos & borregos & alarma & prensa \\
\hline Sinaloa & 24/03/1911 & revoltosos & ataque & lucha & telégrafo \\
\hline Sinaloa & $25 / 03 / 1911$ & $\begin{array}{l}\text { revoluciona- } \\
\text { rios }\end{array}$ & aproximación & alarma & prensa \\
\hline San Ignacio & 28/03/1911 & $\begin{array}{l}\text { revoluciona- } \\
\text { rios }\end{array}$ & ataque & huida & prensa \\
\hline Alayá & $30 / 03 / 1911$ & maderistas & aproximación & alarma & telégrafo \\
\hline San Blas & 02/04/1911 & revoltosos & ataque & expectación & prensa \\
\hline Culiacán & 04/04/1911 & rebeldes & aproximación & alarma & telégrafo \\
\hline Culiacán & 11/04/1911 & revuelta & ataque & alarma & prensa \\
\hline Quelite & 15/04/1911 & individuos & $\begin{array}{l}\text { servicio de } \\
\text { armas }\end{array}$ & $\begin{array}{l}\text { lucha y } \\
\text { locura }\end{array}$ & $\begin{array}{l}\text { parte } \\
\text { oficial }\end{array}$ \\
\hline Quelite & 18/04/1911 & sediciosos & borregos & $\begin{array}{l}\text { alarma y } \\
\text { huida }\end{array}$ & prensa \\
\hline Noria & 25/04/1911 & rebeldes & ataque & alarma & Prensa \\
\hline Mazatlán & $11 / 05 / 1911$ & federales & bombardeos & alarma & $\begin{array}{l}\text { parte } \\
\text { oficial }\end{array}$ \\
\hline Culiacán & 15/05/1911 & $\begin{array}{l}\text { revoluciona- } \\
\text { rios }\end{array}$ & borregos & alarma & prensa \\
\hline
\end{tabular}

Fuente: elaboración propia a partir de datos recopilados del periódico El Correo de la Tarde de Mazatlán, Sinaloa, entre los meses de enero y mayo de 1911. (*) Perteneciente a Durango, (a) aproximación, (b) borregos.

extendió rápidamente entre los vecinos del lugar, que lo transmitían y esparcían a las demás comarcas. De vecino a vecino, el rumor tomaba más fuerza, casi siempre se distorsionaba, y llegaba más rápido a las ciudades por medio de quienes se desplazaban (viajeros, empleados públicos, carteros, comerciantes). 
Debido a la naturaleza de los rumores, los casos de autosugestión eran más comunes de lo que parece, a pesar de que siempre había quienes se tomaban estas alarmas con más tranquilidad y serenidad, el pánico se apoderaba de una gran mayoría. "La autosugestión interviene cuando creen ver y oír, propagando el pánico en los ejércitos, pueblos, etc., sobre todo de noche, donde desencadenan alarmas que generaban el gran pánico" (Lefebvre, 1986, p. 70).

En una ocasión, El Correo de la Tarde reportó una alarma sobre la aparición de sospechosos cerca del pueblo del Quelite. Este hecho propagó tremendo pánico entre sus habitantes, donde los más temerosos se fueron a dormir a los montes cercanos, mientras que otros salieron por rumbos desconocidos; y los que no se creyeron el borregote, cerraron las puertas como de costumbre. Resultó que dichos sospechosos eran un empresario y unos empleados del correo que venían de Mazatlán al Quelite. ${ }^{14}$

Otros medios de comunicación de la época como el telégrafo y el teléfono eran propicios para esparcir las alarmas y los borregos. Estos aparatos modernos a los que no todos podían tener acceso, se encontraban en las oficinas gubernamentales, centros urbanos, y compañías mineras. Estaban al servicio de la clase alta, como algunos comerciantes, mineros, militares, etc. En otros casos, se dieron situaciones en las que informaban sobre estos ataques, esparciéndolos hacia los centros urbanos. A los medios de comunicación se les suele asociar como intachables, que trasmiten la verdad, la objetividad, por lo que en muchos casos se trataba de una realidad y un fiel reflejo de ella, y la verdad despertaba la inseguridad incluso más que noticias fantasiosas entre la sociedad (Zires, 1995, pp. 158-160).

En cierta ocasión un telegrama que llegó a la redacción de $E l$ Correo de la Tarde informaba, sobre los rumores que corrían en Badiraguato, que éste sería atacado por un grupo de revolucionarios. Esto motivó que los vecinos y las autoridades lograran dominar el miedo y la situación, sin llegar a alarmar a toda la población. La localidad mantuvo su confianza y la capacidad para repeler el ataque; hizo los preparativos debidos y armó siete secciones de diez hombres y comandadas por miembros del ejército federal y las autoridades lograron reunir más elementos voluntarios de la localidad para la Guardia Nacional. Con esos preparativos Badiraguato reforzó su seguridad, con lo que quedó dispuesta a repeler cualquier agresión. ${ }^{15}$

\footnotetext{
14 Editorial. (24 de febrero de 1911). Del Quelite. El Correo de la Tarde, Mazatlán, p. 4.

15 El Corresponsal. (28 de febrero de 1911). Siguen los borregos. El Correo de la Tarde, Mazatlán, p. 4.
} 
En otra ocasión se reportó en el puerto de Mazatlán, que hasta entonces permanecía a salvo de las incursiones revolucionarias, sobre un grito desaforado de un pregonero que gritaba: "jatención, aviso al público!". Alertó a la población que creía tener a los revoltosos encima y, con ese motivo, el miedo hizo su aparición y quedó expresado en la prensa, con la siguiente mención: "la sangre se fue a los talones, pero no fue así y por lo tanto se nos volvió el alma al cuerpo". ${ }^{16}$

Otros borregos que también despertaron incertidumbre fueron los que hablaron del servicio a las armas, a lo que la población temía porque sería enlistada al ejército para defender alguna plaza. En ocasiones el retraso del tren, la ausencia del servicio de correo o de periódicos, podía alimentar el rumor que circulaba en una ciudad, convirtiendo estas situaciones en una espera angustiosa. Por ello, durante la guerra contra los rebeldes se suscitaron algunas escenas sobre el temor de la población y que sacados de su cotidianidad mostraron su desasosiego de ir a la guerra. En ese sentido,

En una ocasión un empresario de cinematógrafo salió para Pánuco, a dar algunas funciones, al llegar el mozo que lo acompañaba le fue quitado para que prestara servicios a la Guardia Nacional, pues se esperaba un ataque durante la noche. Al empresario lo armaron y pudo llegar hasta Cópala, y de allí emprendió a pie hasta Concordia, donde tomó un coche para Mazatlán, el mozo por su cuenta preso y de servicio todo el día y por noche donde pocos fueron los que durmieron tranquilamente durante la noche, al amanecer sin novedad le dieron permiso al mozo para desayunar, pero ensilló un caballo y temeroso de que le hicieran soldado de verdad abandonó el lugar. ${ }^{17}$

Otros medios importantes fueron las partes oficiales, correspondientes a las autoridades militares, que en ocasiones aparecían en la prensa:

Nuevos informes oficiales nos hacen saber que veinte rebeldes han aparecido en el rancho de las Tescalama [Distrito de Sinaloa] distante aquí unos veinte kilómetros. Anoche hubo una gran alarma en esta población por la exageración con que se propagaron las noticias recibidas. Tomaban mayores proporciones al grado de que al entregarse al descanso el vecindario, todos creíamos que los insurrectos eran

16 Editorial. (8 de marzo de 1911). Alarma. El Correo de la Tarde, Mazatlán, p. 2.

El Corresponsal. (8 de marzo de 1911). De Pánuco. El Correo de la Tarde, Mazatlán, p. 3. 
trecientos y que a media noche principiaría el ataque de la plaza todo esto fue producto de la imaginación. ${ }^{18}$

Las reacciones más comunes que padecían los habitantes de estos lugares frente al rumor, la alarma y el pánico, fueron emociones donde se debía huir para buscar seguridad. También hubo ocasiones en que sensaciones como la expectación y la serenidad fueron importantes para poder lidiar con el miedo; para luchar y defenderse de los revolucionarios. Aunque este tipo de reacciones nunca predominaron, siempre le acompañaban diferentes actitudes por parte de la población, siendo la alarma lo que reinó en la mayoría de los casos encontrados.

La trasmisión de estos rumores y alarmas era mediante una especie de ciclo o circularidad: idea que parte de los avistamientos de revolucionarios que merodeaban por la sierra generando alarmas a los vecinos, pueblos, aldeas y minerales serranos, inmediatos al acecho de las bandas revolucionarias. Llegaban a las ciudades y los centros poblados más grandes, donde se esparcían a todos lados, haciéndose incontrolables para la autoridad, apoderándose el miedo a través de una espera dolorosa. Para dar un ejemplo véase el siguiente esquema:

\section{Esquema 1}

Los rumores y su propagación
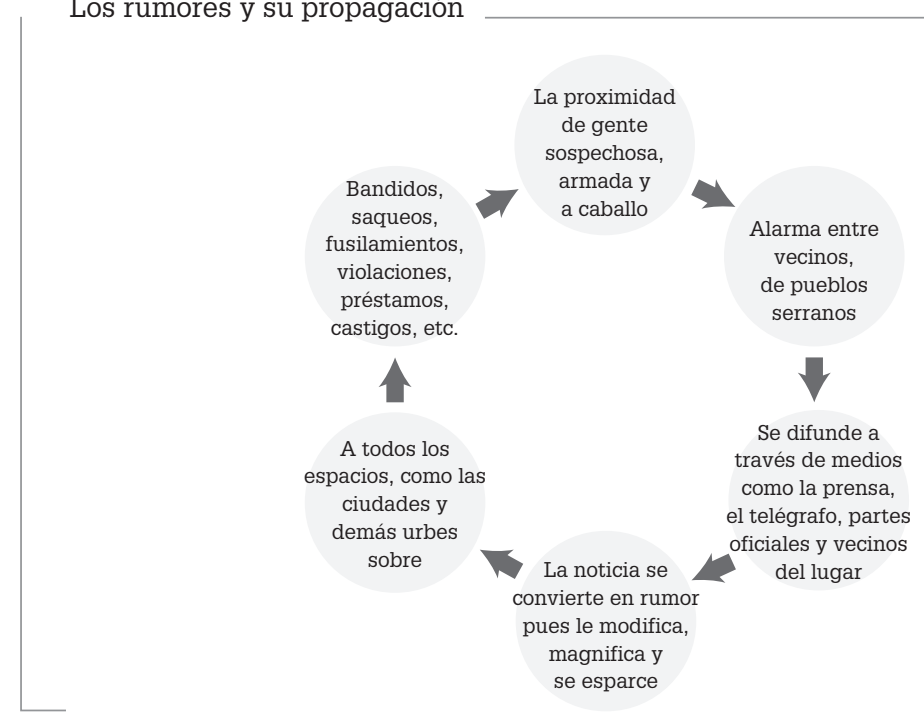

${ }_{18} \begin{aligned} & \text { El Corresponsal. (25 de marzo de 1911). Información oficial. El Correo de la Tarde, Ma- } \\ & \text { zatlán, p. 3. }\end{aligned}$ 
Aunque las imágenes gráficas suelen dar un aspecto más real de la situación, en estas notas periodísticas se refleja parte de la realidad que vivían aquellas poblaciones. Estos temores padecidos durante la contienda primero llegaban a través de los sentidos, donde la vista y el oído jugaban un papel muy importante, que en ocasiones creaban verdaderos momentos de autosugestión. Los ruidos, murmullos, sonidos particulares de la caballada, balazos al aire, instrumentos como el clarín, trompetas o tambores, en unión hacían desencadenar momentos de gran alarma alterando las conductas y las emociones colectivas de estas poblaciones que viven bajo el gran miedo.

\section{La Sierra Madre Occidental, cuna de bandidos y rebeldes}

La Sierra Madre jugó un papel importante en la aparición de los revolucionarios y la difusión de rumores, ya que conectó con numerosos pueblos mineros, ranchos y haciendas donde, al término de las cosechas en invierno y el agotamiento de los trabajos, los borregos aparecieron para cubrir con mayor facilidad esta zona geográfica.

En el siglo XIX el gobierno porfirista persiguió tenazmente a los perturbadores de la paz, como al más famoso Heraclio Bernal, que sobresalió por sus audaces golpes en la serranía sinaloense; junto a sus seguidores infundía pánico a las autoridades porfiristas desapareciendo en los montes y bosques. El principal temor del gobierno fue hacia la subversión y las revueltas armadas que representan el rompimiento del orden y la estabilidad. El miedo a la violencia se asociaba a la aparición de los bandidos en la sierra sinaloense, quienes perpetraban la paz y la tranquilidad con sus movimientos. En 1880, durante la rebelión del exgeneral Jesús Ramírez Terrón, el bandolero Bernal atacó los cuarteles federales, tomó pueblos y asaltó almacenes. Allí, las autoridades sentían pavor al escuchar su grito "Aquí está Heraclio Bernal", mientras los ricos temblaban y huían (Ortega y López, 1987, pp. 196-197).

De acuerdo con François-Xavier Guerra (2012), el bandolerismo que Díaz logró eliminar casi en su totalidad al inicio de su régimen, subsistió en algunas ocasiones, mientras que en otras reapareció en regiones aisladas. Una de estas zonas fue la sierra de Sinaloa, región montañosa de minas antiguas, pequeños mineros y agricultura precaria, que fue teatro del bandolerismo social de Heraclio Bernal, zona de acción privilegiada (Rosario, Plomosas, San Dimas, Tamazula y Topia), donde todo ese territorio en decadencia se convirtió en una de las más activas zonas revolucionarias (p. 259). 
Por otro lado, las partidas rebeldes que recuerdan al bandolerismo comenzaron a actuar en las zonas serranas, en busca de lugares para robar y saquear suministros, armas, dinero y ganado. Para ello, utilizaban los mismos corredores naturales de la zona serrana de Durango y Sinaloa, incrementando la violencia y la inseguridad. Cabe mencionar que las partidas de bandidos durante el porfiriato eran grupos pequeños, oscilando entre los 5 y 20 integrantes; durante la revolución estas partidas integraron compañías y batallones enteros de 100 a 300 integrantes.

Muchos de los rebeldes sinaloenses obtuvieron su aprendizaje revolucionario directamente de la sierra, como Ramón F. Iturbe, oriundo de la costa del Pacífico y que se lanzó a las montañas para organizar grupos rebeldes luego de que los porfiristas lo descubrieran en plena conspiración el 19 de noviembre de 1910. También está el caso de Juan Banderas, notable vaquero de las haciendas de Badiraguato y caballerango del gobernador de Sinaloa, Diego Redo, que junto a José María Cabanillas y Francisco Quintero cubrieron con sus guerrilleros la zona de la sierra de Badiraguato hasta la costa. En otro caso los chileros de Durango, Herculano y Nabor de la Rocha, que con sus peones se sumaron a la lucha; y Juan Carrasco, que era señalado como un criminal (Ortega, 1999, p. 168).

Alan Knight (2010) menciona que este bandidaje se confundía con el movimiento rebelde, donde muchos de los guerrilleros revolucionarios tenían antecedentes criminales, además de ser extraordinarios jinetes y buenos tiradores. Las gavillas se diferenciaron de las bandas rebeldes porque no tenían afinidad y distaban de un programa político, pero su imagen y su movimiento elevaron el sentimiento de inseguridad entre los habitantes del mundo rural (p. 256).

Aunque la paz forzada del Porfiriato exigió el control autoritario del poder político, conllevó un cierto control emocional, pues el orden daba seguridad y estabilidad mental. En el antiguo régimen los miedos desatados por el desborde de la violencia eran atendidos mediante la acción continua del Estado. Con la revolución y el orden social subvertido, éstos no podían ser amparados, ya que la normalidad se había quebrado y el sentimiento de inseguridad se apoderó de la población. Tal sensación fue descrita en el periódico El Correo de la Tarde, al decir que en los poblados de El Rosario y Concordia, personas manifestaron que se estaban quedando solos. La gente que los domingos acostumbraba llegar de los ranchos vecinos para hacer sus compras, se había abstenido de ir a la ciudad por temor de ser reclutada:

En Concordia la situación era lamentable, muchos negocios e industrias permanecían cerradas y lo único que prometía esperanzas era la 
agricultura, pero como abundaban los borregos, los hombres labradores huyeron al campo dejando esposas e hijos, se afirma que la única ocupación del pueblo era el trabajo en las milpas donde los únicos que quedaban eran algunos empleados y uno que otro propietario y que esta situación se debía a que tenían miedo de que se les obligase hacer guardia o que se les consignara al servicio de las armas. ${ }^{19}$

Existe alarma por tantas prisiones y el comercio y en general toda clase de negocio padecerán con estos sucesos y varios establecimientos se verán quizás en la imperiosa necesidad de cerrar sus puertas, debido a la falta de movimiento comercial. Ojalá que esto no suceda y que pronto estas persecuciones cesan, y nos vuelva, como antes, la tranquilidad que disfrutamos. Aquí no hay sediciosos, sino gente trabajadora. ${ }^{20}$

El estruendo de las armas de fuego y el efecto psicológico que produjo el hecho de que pudieran herir o matar a distancia fue suficiente para atemorizar y paralizar a quienes ya tenían noticias de los estragos que podían causar. Una de las primeras expresiones de los sentimientos del hombre en sociedad ha sido el miedo al extraño, el temor a lo desconocido, una disposición natural a creer que las novedades son potencialmente peligrosas y, como consecuencia, el rechazo y la justificación de la violencia. Por eso lo nuevo engendra miedo. La naturaleza humana favorece el miedo porque es un recurso de protección (Gonzalvo, Staples y Torres, 2009, pp. 24, 41).

Las montañas de la Sierra Madre ofrecieron refugio a estos bandidos. A menudo, el nexo entre bandolero y bandido revolucionario era estrecho y tradicional, pues compartían sentimientos y relaciones antiguas. Cuando los perseguidores del gobierno se internaban en territorio serrano, surgía el carácter social de los bandidos, ya que inmediatamente ponían en contra a la gente de los pueblos y rancherías al proteger a malhechores para vengar los agravios en contra de las autoridades por asuntos del terreno mancomunado; los bandidos gozaban de cierta mística y popularidad (Knight, 2010, p. 188).

Cuando estalló la rebelión popular, el bandido, con sus habilidades especiales, conocimiento de la localidad y reputación popular, alcanzó un sitio prominente. Los vagabundos de la sierra volvieron a aparecer en el

\begin{tabular}{l|l}
19 & El Corresponsal. (17 de febrero de 1911). De Concordia. El Correo de la Tarde, Mazatlán, \\
p. 3. & El Corresponsal. (21 de febrero de 1911). Del Rosario. El Correo de la Tarde, Mazatlán, \\
p. 2.
\end{tabular} 
escenario de la Revolución; muchos, llevados por intereses personales por la simpatía plebeya hacia los rebeldes, aumentaron en número diariamente con el descontento de los pueblos serranos hacia el régimen. Los movimientos rebeldes no sólo eran de carácter violento, sino que establecían alianzas que abarcaban a terratenientes, campesinos, arrieros y bandoleros; la imagen tradicional del bandido de antaño se asemejó a una visión romántica (Knight, 2010, pp. 186-191).

En el caso francés, Georges Lefebvre observó que durante la revolución de 1789, muchos asociaban el pavor que se alimentaba con la aparición de bandidos y vagabundos que se movían en los bosques con la intención de saciar su hambre y miseria contra los pobres campesinos. Por ello, el avistamiento de un grupo de dos mendigos divisados en el campo desataba grandes alarmas que alborotaban toda una región (Lefebvre, 1986, pp. 213-214).

Perea (2009) señala que durante la revuelta zapatista en Sinaloa los "rebeldes se adentraban a los pueblos mediante el efecto práctico del miedo, como estrategia propagando una serie de rumores, los cuales se encargaban de alertar a la población, infundiendo la alarma, confusión y expectativa". Ello se debió a que muchas veces se tuvo la certeza de que estos grupos rebeldes actuaban con mucha violencia. Se les representaba colectivamente como salvajes y bárbaros que utilizaban los asesinatos sanguinarios, violaciones y amenazas de muerte como efecto psicológico para conseguir de ello lo que quisieran (pp. 166-174).

En Sinaloa, el revolucionario era asociado con el bandido; en ocasiones eran apoyados, pero su presencia despertaba pánico ante la violencia. Al mismo tiempo que proliferaron los rumores y las falsas alarmas, se incrementaron las operaciones rebeldes, dando como resultado el resurgimiento de un viejo problema como el bandolerismo, que se desarrolló sobretodo en el sur de Sinaloa, donde bandidos y gavillas aprovecharon el vacío de poder que originó la revolución para internarse en las zonas rurales.

\section{Conclusión}

Es indudable que en Sinaloa los rumores o "borregos lanudos" causaron gran miedo dentro de la población, principalmente de los núcleos urbanos, debido a que se presentaba una necesidad de informarse sobre los sucesos de la guerra revolucionaria que se desarrollaba en la región serrana del estado. Ello se recrudecía si las alertas hablaban de hechos violentos y atropellos cometidos por los revolucionarios contra los pobladores. A diferencia del caso francés que estudió Lefebvre, en Sinaloa no 
se hablaban de falsos rumores, ni el inminente arribo de bandidos o sucesos que generaran temores; los sucesos constatados antes de ser referidos oralmente trataban de una realidad anunciada y crearon un marcado sentimiento de inseguridad en el que cayeron mujeres y hombres (Ojeda, 2011, pp. 184-185).

Queda expuesto que la manifestación del miedo durante la revolución se debió a peligros reales, derivados de la guerra misma, donde las creencias y el comportamiento del sinaloense fueron influenciados por el rumor, la ficción, y la prensa. Había también una intencionalidad por parte de El Correo de la Tarde de publicarlos, como opositor al régimen porfirista, por lo que muchos corresponsales transmitían estas noticias como "oficiales", pues aseguraban haberlas corroborado a través de diversos medios.

De acuerdo El Correo de la Tarde, los "borregos" eran recopilados por el periódico a partir de lo que decían de boca en boca los vecinos de los lugares afectados, y otros medios de comunicación como el telégrafo y teléfono. Todos propagaron los rumores y despertaron el miedo entre los sinaloenses.

Las alarmas fueron diversas: podían ser el avistamiento de hombres sospechosos, armados y a caballo, la aproximación de los rebeldes en algún punto geográfico, el robo de ganado, el saqueo de pueblos, minas y haciendas en la sierra, asaltos, robos por parte de los bandidos en los caminos, etc., así como la leva o el servicio de las armas por parte de los federales.

La circularidad de los rumores obedecía al flujo de información. Mediante redes de comunicación de la época se advirtió lo que acontecía en la sierra como punto más próximo que padeció la violencia revolucionaria a las ciudades, las cuales intercambiaban información por medio de viajeros, vecinos que huían, empleados del periódico, del correo, del gobierno, comerciantes y trabajadores. Estos personajes hablaban acerca de lo que veían y oían, que, con ayuda de la difusión de la prensa, alimentaron el miedo del resto de la población.

En la revolución, los rumores permearon la sensibilidad colectiva, lo cual produjo algunos cambios de comportamiento. La búsqueda de la seguridad personal y de los bienes propios, o en su defecto la lucha y defensa del pueblo, en la mayoría de los casos se convertían en una espera angustiosa bajo el contexto del gran miedo.

\section{Archivo}

Archivo General de la Nación (AGN)

Fondo del Instituto Nacional de Estudios Históricos de la Revolución Mexicana (INEHRM) Fotos. 


\section{Hemerografía}

El Correo de la Tarde. Mazatlán, Sinaloa, 1911.

El Monitor Sinaloense. Culiacán, Sinaloa, 1911.

Spokane Daily Chronicle. Spokane Falls, Oregon, 1911.

\section{Referencias bibliográficas}

Allport, G. y L. Postman. (1988)

Psicología del rumor. Buenos Aires: Editorial Psique.

Bloch, M. (2003)

La extraña derrota. Barcelona: Crítica.

Contreras Orozco, J. (2001)

Rumores: Voces que serpentean. Revista Latina de Comunicación Social, 40, http://www.revistalatinacs.org/2001/latina40abr/108contreras. htm

Delumeau, J. (2013)

El Miedo en Occidente. México: Taurus.

Gonzalbo P., Sataples, A., Torres, v. (2009)

Una historia de los usos del miedo. México: El Colegio de México.

Guerra, F. X. (2012)

Del antiguo Régimen a la Revolución II. México: Fondo de Cultura Económica.

Knight, A. (2010)

La Revolución mexicana, Del Porfiriato al nuevo régimen Constitucional. México: Fondo de Cultura Económica.

Lefebvre, G. (1986)

El gran pánico de 1789 la Revolución francesa y los campesinos. Barcelona: Paidós.

Macías, C. (2015)

El simbolismo de la oveja y su presencia en la obra de Picasso. Repositorio Institucional de la Universidad de Málaga (RIUMA), Vol. n/c, recuperado de https://riuma.uma.es/xmlui/handle/10630/10521 p. 17.

Molina, L. F. (2003)

El mundo de Molina. Culiacán: COBAES, Dirección de Investigación y Fomento de Cultura Regional, La crónica de Culiacán.

Perea, D. M. (2009)

La rebelión zapatista en Sinaloa (Tesis de Maestría en Historia). Universidad Autónoma de Sinaloa.

Olea, H.R. (2010)

La Revolución en Sinaloa. México: Creativos7 Editorial.

Ojeda Gastélum, S. O. (2011)

Sinaloa: Temores, Angustias e Infortunios, durante los primeros años 
revolucionarios En S. O. Ojeda Gastélum y M. H. Lazcano Armienta (Coord.), Historia de la Revolución en Sinaloa. México: Universidad Autónoma de Sinaloa, pp. 147-185.

Ortega, S. y López M. E. (1987)

Sinaloa una historia compartida, México: Dirección de Investigación y Fomento de la Cultura Regional.

Ortega, S. (1999)

Breve Historia de Sinaloa, México: Fondo de Cultura Económica.

Quintero, F. (2007)

Historia integral del río Fuerte, México: Creativos 7 Editorial, p. 355.

Rosas, C. L. (2006)

Del Trono a la guillotina. El impacto de la Revolución francesa en el

Perú (1789-1808). Lima: Fondo Editorial de la Pontificia Universidad Católica del Perú.

Van Dijk, T. (1990)

La noticia como discurso. Comprensión, estructura y producción de la información. Barcelona: Editorial Paidós.

Vargas, L. A. (2012)

Miedo, sufrimientos e inseguridades en los Altos de Jalisco durante la revolución mexicana. (Tesis de Maestría inédita). Universidad de Guadalajara, México.

Vovelle, M. (1989)

Mentalidad Revolucionaria. Barcelona: Crítica.

Zires, M. (1995)

La dimensión cultural del rumor. Comunicación y Sociedad, 24, 155176. 